\title{
Porphyromonas gingivalis Gingipains-Mediated Degradation of Plasminogen Activator Inhibitor-1 Leads to Delayed Wound Healing Responses in Human Endothelial Cells
}

\author{
Li-Ting Songa, ${ }^{a}$ Hiroyuki Tada ${ }^{a}$ Takashi Nishioka $^{c}$ Eiji Nemoto ${ }^{d}$ \\ Takahisa Imamura ${ }^{\mathrm{e}}$ Jan Potempa ${ }^{\mathrm{f} g}$ Chang-Yi Li ${ }^{\mathrm{b}}$ Kenji Matsushita ${ }^{\mathrm{h}}$ \\ Shunji Sugawara ${ }^{a}$
}

aDivision of Oral Immunology, Tohoku University Graduate School of Dentistry, Sendai, Japan; bHospital of Stomatology, School of Dentistry, Tianjin Medical University, Tianjin, China; 'Division of Oral Diagnosis, Tohoku University Graduate School of Dentistry, Sendai, Japan; dDivision of Periodontology and Endodontology, Tohoku University Graduate School of Dentistry, Sendai, Japan; 'Department of Nutritional Science, Faculty of Human Life Science, Shokei University, Kumamoto, Japan; fDepartment of Microbiology, Faculty of Biochemistry, Biophysics, and Biotechnology, Jagiellonian University, Kraków, Poland; ${ }^{9}$ Department of Oral Immunology and Infectious Diseases, University of Louisville School of Dentistry, Louisville, KY, USA; ' Department of Oral Disease Research, National Center for Geriatrics and Gerontology, Obu, Japan

\section{Keywords}

Bacterial infection · Endothelial cells · Pathogenesis ·

Wound healing $\cdot$ Periodontitis

\begin{abstract}
Plasminogen activator inhibitor-1 (PAl-1), a serine protease inhibitor, is constitutively produced by endothelial cells and plays a vital role in maintaining vascular homeostasis. Chronic periodontitis is an inflammatory disease characterized by bleeding of periodontal tissues that support the tooth. In this study, we aimed to determine the role of PAI-1 produced by endothelial cells in response to infections caused by the primary periodontal pathogen Porphyromonas gingivalis. We demonstrated that $P$. gingivalis infection resulted in significantly reduced PAI-1 levels in human endothelial cells. This reduction in PAl-1 levels could be attributed to the proteolysis of PAl-1 by P. gingivalis proteinases, especially lysinespecific gingipain-K (Kgp). We demonstrated the roles of
\end{abstract}

karger@karger.com www.karger.com/jin

Karger"

BOPEN ACCESS
(C) 2021 The Author(s)

Published by S. Karger AG, Basel

This is an Open Access article licensed under the Creative Common Attribution-NonCommercial-4.0 International License (CC BY-NC) (http://www.karger.com/Services/OpenAccessLicense), applicable to the online version of the article only. Usage and distribution for commercial purposes requires written permission. these degradative enzymes in the endothelial cells using a Kgp-specific inhibitor and P. gingivalis gingipain-null mutants, in which the lack of the proteinases resulted in the absence of PAl-1 degradation. The degradation of PAI- 1 by $P$. gingivalis induced a delayed wound healing response in endothelial cell layers via the low-density lipoprotein receptor-related protein. Our results collectively suggested that the proteolysis of PAI- 1 in endothelial cells by gingipains of $P$. gingivalis might lead to the deregulation of endothelial homeostasis, thereby contributing to the permeabilization and dysfunction of the vascular endothelial barrier.

(C) 2021 The Author(s).

Published by S. Karger AG, Basel

\section{Introduction}

Chronic periodontitis is characterized by a cumulative inflammatory burden induced by persistent infection caused by periodontopathic bacteria, leading to bleeding, 
fibrinolysis, and inflammation. The pathogenesis of chronic periodontitis positively correlates with the presence of the keystone pathogen Porphyromonas gingivalis in the periodontal pockets and atherosclerotic plaques $[1-3]$. P. gingivalis is most frequently identified in the blood vessels of patients with chronic periodontitis [4], where it induces adherence of the bacteria to endothelial cells in blood vessels, and causes events that are implicated in the induction of vascular inflammation [5]. The bacteria utilize diverse virulence factors that manipulate the immune responses of the host, thereby inducing chronic inflammation and bone loss. $P$. gingivalis synthesizes two types of cysteine proteinases, arginine-specific gingipains (RgpA and RgpB) and lysine-specific gingipain (Kgp) $[6,7]$, which induce the production of proinflammatory cytokines, leading to chronic inflammation and destruction of periodontal tissues, including alveolar bone and tooth loss [7]. However, gingipains also proteolytically degrade host molecules including those in complement system, CD14, and intercellular adhesion molecule- 1 and cytokines such as interleukin (IL)- $1 \beta$, IL6 , IL-8, interferon- $\gamma$, and tumor necrosis factor- $\alpha$, leading to the escape of $P$. gingivalis from the innate immune responses and resulting in persistent inflammation in the periodontal tissues [8].

The plasminogen activation system regulates vascular homeostasis via plasmin, an active form of serine protease, to degrade fibrin into fibrin degradation products. The conversion of plasminogen into plasmin occurs via the binding of plasminogen to the plasminogen activators (PAs), that is, tissue-type plasminogen activator (tPA) and urokinase-type plasminogen activator (uPA). Plasminogen activator inhibitor type 1 (PAI-1) is a serine proteinase inhibitor that primarily inhibits PAs. PAI-1 is expressed on platelets and endothelial cells in the blood vessels and fibroblasts, platelets, macrophages, hepatocytes, adipocytes, and the mesothelial cells of the inflamed tissues $[9,10]$. PAI-1 produced by endothelial cells supports their maintenance by regulating vascular remodeling and wound healing by inducing cell migration, angiogenesis, and inflammation in the vascular endothelium [10-14]. Furthermore, congenital PAI-1 deficiency, an autosomal recessive disease, is characterized by a bleeding tendency with minor wounds and impaired wound healing because of the lack of PAI-1 functions [15-17]. However, excessive PAI-1 levels are associated with pathophysiological phenomena, such as cardiovascular disease, tissue fibrosis, and cancer [18].

Most oral bacteria have been identified in the blood cultures of patients after tooth brushing or during dental procedures [19]. P. gingivalis and gingipains play a vital role in exacerbating the pathogenesis of systemic conditions involving blood vessel dysfunction $[1,2,20]$. It has been reported that intensive periodontal treatment of patients with chronic periodontitis ameliorates systemic inflammation and vascular endothelial function [21]. $P$. gingivalis has also been detected in the brain tissues or aneurysmal tissues of patients with Alzheimer's disease or atherosclerosis, respectively $[20,22]$. The $P$. gingivalis gingipains colonizing the brain in Alzheimer's disease were neurotoxic [20]. Coculturing of human platelets with $P$. gingivalis resulted in decreased $\mathrm{Pam}_{3} \mathrm{CSK}_{4}$-induced PAI-1 production [23]. These findings suggest that decreased PAI-1 production in response to P. gingivalis possibly plays a role in the pathogenesis of systemic diseases associated with blood vessel barrier dysfunction.

In the present study, we focused on the impact of $P$. gingivalis on the production of PAI-1 by endothelial cells. We also investigated the role of PAI-1 in modulating the endothelial barrier. Our results indicated that $P$. gingivalis gingipains proteolytically degraded PAI-1 produced by human endothelial cells, resulting in a delayed wound healing response. The results from this study suggest that gingipain-mediated degradation of PAI-1 in endothelial cells may promote periodontal tissue bleeding in periodontal disease, induce the destruction of periodontal tissues, and lead to the spread of $P$. gingivalis infection from these tissues to the systemic organs via the bloodstream.

\section{Materials and Methods}

\section{Reagents}

Gingipain inhibitors KYT-1 and KYT-36 were obtained from the Peptide Institute (Osaka, Japan). KYT-1 is an Rgp-specific inhibitor and KYT-36 is a Kgp-specific inhibitor [24]. The PAI-1 antagonist PAI-039 tiplaxtinin was obtained from MedChemExpress (Monmouth Junction, NJ, USA). Recombinant human receptor-associated protein (RAP) and recombinant human PAI-1 (rhPAI-1) mutant were obtained from Sigma-Aldrich (St. Louis, MO, USA). RAP is an antagonist of the low-density lipoprotein receptor-related protein (LRP). It is known that wild-type PAI-1 is not stable and gets converted into an inactive latent form, with a half-life ranging between 1 and $2 \mathrm{~h}$ [25]. The rhPAI- 1 mutant is an altered form of human PAI-1 containing 4 mutated amino acids that markedly improved functional stability, because of its inability to convert to the latent form. The residue numbers for the four mutations present in rhPAI-1 mutant are N150H, K154T, Q319L, and M354I [25]. As a consequence, the mutant protein exhibits markedly increased thermal stability of the active form relative to active wild-type PAI-1. All other reagents were purchased from Sigma-Aldrich unless otherwise indicated. 


\section{Cells and Culture Conditions}

Human umbilical vein endothelial cells (HUVECs) were obtained from Lonza (Walkersville, MD, USA). HUVECs were cultured in endothelial cell growth medium-2 (EGM-2) (Lonza), composed of endothelial cell growth basal medium-2 (EBM-2) supplemented with $2 \%$ heat-inactivated fetal bovine serum (FBS), $5 \mathrm{ng} / \mathrm{mL}$ hEGF, $0.5 \mathrm{ng} / \mathrm{mL}$ hVEGF, $20 \mathrm{ng} / \mathrm{mL} \mathrm{R}^{3}$-IGF-1, $1 \mu \mathrm{g} / \mathrm{mL}$ ascorbic acid, $0.2 \mu \mathrm{g} / \mathrm{mL}$ hydrocortisone, $10 \mathrm{ng} / \mathrm{mL}$ hFGF- $\beta, 22.5$ $\mu \mathrm{g} / \mathrm{mL}$ heparin, and $0.1 \%$ gentamicin/amphotericin-B (Lonza) using collagen type I-coated 100-mm dishes (IWAKI ${ }^{\circledR}$; AGC TECHNO GLASS, Shizuoka, Japan). Experiments with $P$. gingivalis live bacteria were performed using EGM-2 without antibiotics. Confluent monolayer cells at passages 5 through 7 were used for the experiments. The viability of the HUVECs after infection with $P$. gingivalis was measured based on the amount of NanoLuc ${ }^{\circledR}$ substrate diffused from the viable cells using the RealTime-Glo MT Cell Viability Assay (Promega, Madison, WI, USA) according to the manufacturer's instructions. The assay involves adding NanoLuc $^{\circledR}$ luciferase and a cell-permeable substrate to cells in culture. The substrate is reduced to NanoLuc ${ }^{\circledR}$ substrate by metabolically active cells, which diffuses from the cells into the culture medium. The luminescence of the NanoLuc ${ }^{\circledR}$ substrate in the culture supernatants was determined using a GloMax ${ }^{\circledR}$ Discover Microplate Reader (Promega). The proliferation of $P$. gingivalis-infected HUVECs was measured using the Cell Counting Kit-8 (Dojindo, Kumamoto, Japan). The number of viable cells was calculated based on the absorbance using SoftMax Pro, a data analysis software (Molecular Devices, Menlo Park, CA, USA).

\section{Purification and Activation of Gingipains}

Kgp and RgpA were purified from the culture supernatants of P. gingivalis HG66, as previously described [6]. Gingipains are stable between room temperature and $37^{\circ} \mathrm{C}$ in the absence of cysteine, which is the most effective reducing agent for activation of the enzyme [6]. The enzymes were diluted to activate gingipains at $10 \mu \mathrm{M}$ in $0.2 \mathrm{M} \mathrm{HEPES}, 5 \mathrm{mM} \mathrm{CaCl}_{2}$, and $10 \mathrm{mmL}$ cysteine at $\mathrm{pH} 8$ and incubated at $37^{\circ} \mathrm{C}$ for $10 \mathrm{~min}$. After activation, they were diluted with complete medium or $0.1 \mathrm{M}$ Tris buffer for the experiments with HUVECs or rhPAI-1, respectively.

Culture of P. gingivalis and Preparation of Whole-Cell Lysates

In this study, we used two wild-type strains and five gingipain mutant strains of $P$. gingivalis to investigate the $P$. gingivalis gingipains-mediated reduction in PAI-1 levels. The strains W83, ATCC 33277, KDP129 $(\Delta k g p), \operatorname{KDP} 131(\Delta r g p A), \operatorname{KDP} 132(\Delta r g p B)$, KDP133 $(\Delta r g p A \Delta r g p B)$, and KDP136 $(\Delta r g p A \Delta r g p B \Delta k g p)$ were cultured anaerobically at $37^{\circ} \mathrm{C}$ for $60 \mathrm{~h}$ in enriched tryptic soy broth containing $1 \%$ tryptone, $3 \%$ tryptic soy, $2.5 \%$ yeast extract, $0.1 \%$ Lcysteine, $5 \mu \mathrm{g} / \mathrm{mL}$ hemin, and $0.5 \mu \mathrm{g} / \mathrm{mL}$ of menadione. After $60 \mathrm{~h}$ of incubation, log-phase bacterial culture was centrifuged for 15 min at 8,500 $\mathrm{g}$ and washed three times with phosphate-buffered saline (PBS). All bacterial strains were cultured on tryptic soy agar plates at $37^{\circ} \mathrm{C}$ under anaerobic conditions. The $\mathrm{CFU} / \mathrm{mL}$ was measured after $72 \mathrm{~h}$ of culture. After being washed three times with PBS, whole bacterial cells in the logarithmic growth phase were resuspended in PBS, lyophilized by centrifugation in vacuo, and then resuspended in the same volume of distilled water. The bacterial cultures were sonicated for $1 \mathrm{~min}$ and then centrifuged for $20 \mathrm{~min}$ at $10,000 \mathrm{~g}$ at $4^{\circ} \mathrm{C}$ to separate bacterial cells from the culture medium and collect outer membrane vesicles (OMVs). Subsequently, the supernatants were ultracentrifuged for $1 \mathrm{~h}$ at $150,000 \mathrm{~g}$ at $4^{\circ} \mathrm{C}$, and the pellet enriched in OMVs was resuspended in $5 \mathrm{mM} \mathrm{MgCl}_{2}$ prepared in PBS. Protein concentrations in the OMV fractions were measured using a bicinchoninic acid (BCA) protein assay.

\section{Measurement of Cytokines Production Using an Enzyme-}

\section{Linked Immunosorbent Assay}

The concentrations of PAI- 1 in the culture supernatants were measured using enzyme-linked immunsorbent assay kits $(\mathrm{R} \& \mathrm{D}$ Systems, Minneapolis, MN, USA) according to the manufacturer's instructions. The concentrations of the cytokines were calculated from the absorbance using a data analysis program (SoftMax Pro; Molecular Devices).

Reverse Transcription and Quantitative Real-Time Polymerase Chain Reaction

Isolation of total RNA, reverse transcription, and real-time quantitative polymerase chain reaction (PCR) assays were performed. Total cellular RNA was extracted using an RNeasy ${ }^{\circledR}$ kit (Qiagen Inc., Valencia, CA, USA) with DNase treatment (RNasefree DNase set; Qiagen) according to the manufacturer's instructions, and $500 \mathrm{ng}$ of total RNA were reverse-transcribed into 500 ng of cDNA using a Transcriptor First Strand cDNA Synthesis Kit ${ }^{\circledR}$ (Roche Diagnostic Co., Indianapolis, IN, USA). Polymerase chain reactions were performed with SsoAdvanced Universal SYBR Green Supermix (Bio-Rad Laboratories, Hercules, CA, USA) using $50 \mathrm{ng}$ of cDNA and the primers in an Applied Biosystems 7500 System $^{\circledR}$ (Thermo Fisher Scientific, Waltham, MA, USA) under the following amplification conditions: 40 cycles of $95^{\circ} \mathrm{C}$ for $15 \mathrm{~s}$ and $60^{\circ} \mathrm{C}$ for $60 \mathrm{~s}$. Primers were designed using LightCycler probe design software ${ }^{\circledR}$ (Roche Diagnostics Co., Mannheim, Germany). The following are the sequences of the primer used in the study (forward/reverse): human PAI-1 (5'-TCATAGTCTCAGCCCGC-3'; 5'-CCTTCAGAAAGAGTCATTAACAC-3'); and human GAPDH ( $5^{\prime}$-TGAACCATGAGAAGTATGACAACA- $3^{\prime} ; 5^{\prime}$-TCTT CTGGGTGGCAGTG-3'). The relative induction of PAI-1 mRNA expression was determined after normalization to the GAPDH reference gene, whose expression level was defined as 1 .

Detection of PAI-1 by Western Blotting and Silver Staining

The cell lysates were prepared using Cell Lysis Buffer (Cell Signaling Technology, Beverly, MA, USA) after infecting the HUVECs with $P$. gingivalis. Proteins $(4 \mu \mathrm{g})$ from the cell lysates were separated by $12 \%$ SDS-PAGE under reducing conditions to detect the intracellular expression of PAI-1 in HUVECs. The gel was then transferred to a polyvinylidene difluoride membrane (ATTO, Tokyo, Japan). The blots were then blocked using the Bullet Blocking One (Nacalai Tesque, Kyoto, Japan) for $5 \mathrm{~min}$ at room temperature (RT), before being incubated overnight at $4^{\circ} \mathrm{C}$ with mouse antiPAI-1 mAb (Santa Cruz Biotechnology, Dallas, TX, USA) at 0.4 $\mu \mathrm{g} / \mathrm{mL}$ (1:500), and horseradish peroxidase-conjugated horse antimouse IgG (Cell Signaling) at 1:2,000 for $1 \mathrm{~h}$ at RT.

For the detection of enzymatic digestion of rhPAI-1, $0.2 \mu \mathrm{g}$ ( 454 nM) of rhPAI-1 (BioLegend, San Diego, CA, USA) was treated with $0.095 \mu \mathrm{g}(45.4 \mathrm{nM})$ of purified Kgp or $0.086 \mu \mathrm{g}(45.4 \mathrm{nM})$ of RgpA, at an enzyme:substrate (E:S) molar ratio of $1: 10$ in $0.1 \mathrm{M}$ Tris- $\mathrm{HCl}$, $\mathrm{pH}$ 7.6, containing $150 \mathrm{mM} \mathrm{NaCl}, 5 \mathrm{mM} \mathrm{CaCl}_{2}$, and $0.5 \%$ bovine serum albumin (BSA), incubated at $37^{\circ} \mathrm{C}$ for $15 \mathrm{~min}$, then solubilized with Cell Lysis Buffer (Cell Signaling), and boiled at $95^{\circ} \mathrm{C}$ for $5 \mathrm{~min}$. The aliquots $(0.05 \mu \mathrm{g})$ of rhPAI- 1 were separated by $12 \%$ 
Fig. 1. $P$. gingivalis infection reduces PAI-1 production by human endothelial cells. HUVECs were infected with $P$. gingivalis W83 live bacteria at the indicated MOI (a) for $24 \mathrm{~h}$ or at an MOI of 16 for the indicated times (b). a, b Bar plots quantifying the amount of PAI-1 in the culture supernatants as measured by ELISA. c, d HUVECs were infected with $P$. gingivalis W83 live bacteria at an MOI of 16 for the indicated times. c Total RNA was extracted, converted to cDNA, and RT-qPCR quantified PAI-1 transcripts in control versus infected cells. d Total cell lysates were extracted and analyzed by Western blotting with anti-PAI-1 mAb. Data are representative of three independent experiments and are shown as means \pm SD. Statistically significant differences are indicated as follows: ${ }^{* *} p<0.01 ;{ }^{*} p<0.05$ compared with the respective untreated control. PAI-1, plasminogen activator inhibitor-1; HUVECs, human umbilical vein endothelial cells; MOI, multiplicity of infection; ELISA, enzyme-linked immunosorbent assay.
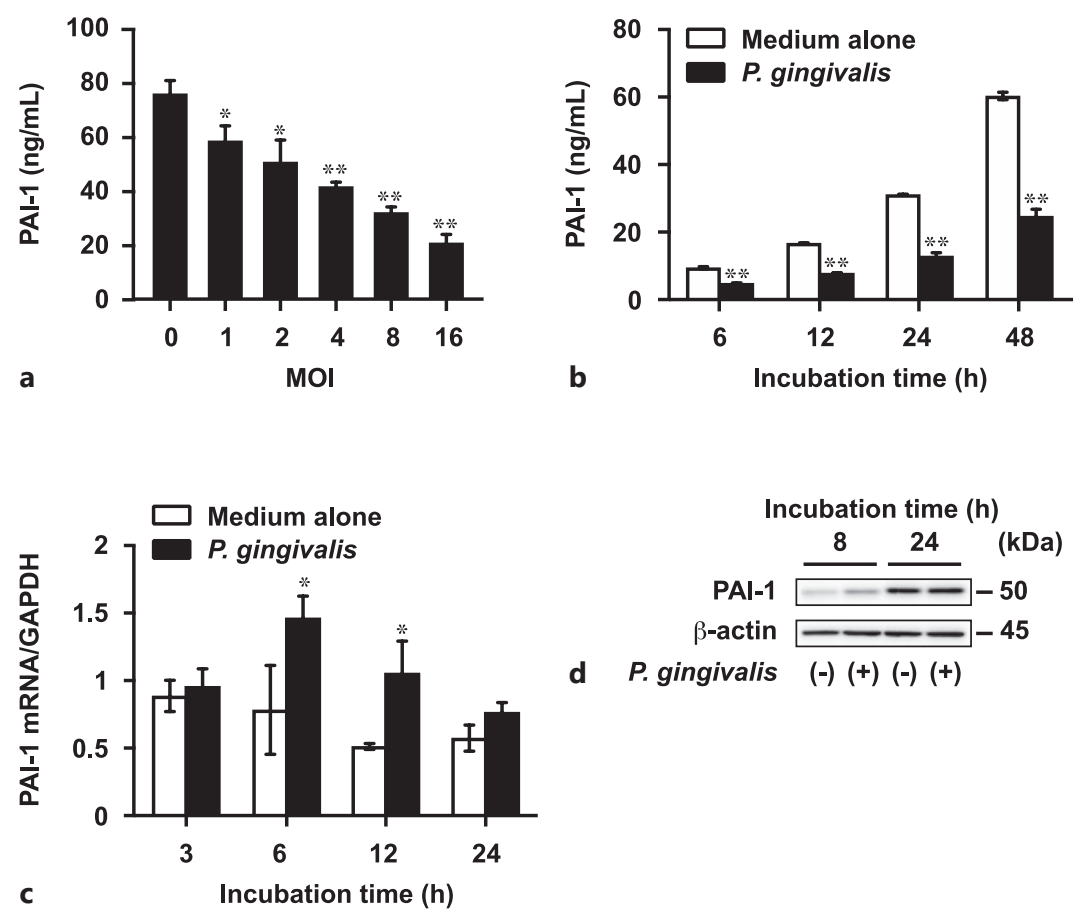

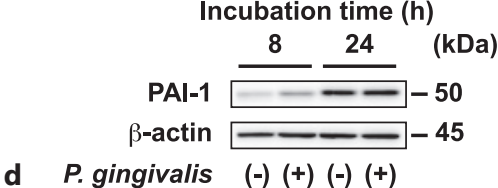

d

$(-)(+)(-)(+)$
SDS-PAGE under reducing conditions. The gel was then transferred to a polyvinylidene difluoride membrane (ATTO). The blots were then blocked using the Bullet Blocking One (Nacalai Tesque) for $5 \mathrm{~min}$ at RT, before being incubated overnight at $4^{\circ} \mathrm{C}$ with mouse anti-His mAb (Fujifilm Wako, Osaka, Japan) at 0.01 $\mu \mathrm{g} / \mathrm{mL}(1: 5,000)$, and horseradish peroxidase-conjugated horse anti-mouse IgG (Cell Signaling) at 1:3,000 for $1 \mathrm{~h}$ at RT.

Finally, the blots were treated with the Chemi-Lumi One Super detection reagent (Nacalai Tesque). The chemiluminescent signal was detected using a FUSION FX luminescent image analyzer (Vilber Smart Imaging, Collegien, France). The intensity of the signals was quantified via densitometry scanning using Image software (https://imagej.nih.gov/ij/), and the results are shown as relative values of the expression compared with that of the untreated control, which was converted to 1 .

\section{Enzyme Activity Assay}

The amidolytic activities of gingipains from live bacterial cells, lyophilized whole cells, and OMVs of $P$. gingivalis W83 or ATCC 33277 were assayed at $37^{\circ} \mathrm{C}$ using $0.5 \mathrm{mM} \mathrm{N}$ - $\alpha$-benzoyl-L-argininep-nitroanilide (BA-pNA) for Rgp and $0.5 \mathrm{~mm}$ Z-His-Glu-Lys4-methylcoumaryl-7-amide for Kgp in $1.0 \mathrm{~mL}$ of $0.2 \mathrm{M}$ Tris- $\mathrm{HCl}, 0.1$ $\mathrm{M} \mathrm{NaCl}, 5 \mathrm{mM} \mathrm{CaCl}_{2}$, and $10 \mathrm{mM}$ cysteine ( $\mathrm{pH}$ 7.6). The absorbance of $p$-nitroaniline or 7-amino-4-methylcoumarin released from the substrate was measured at $405 \mathrm{~nm}$ and $370 \mathrm{~nm}$, respectively.

\section{Assessment of Cell Migration of Endothelial Cells by in vitro} Scratch Assay

An in vitro scratch assay was performed as described previously [26], with some minor modifications to assess the effect of $P$. gingivalis on the migration of endothelial cells. Briefly, HUVECs were cultured to create a confluent monolayer in a collagen type Icoated 24-well plate (IWAKI ${ }^{\circledR}$; AGC TECHNO GLASS). The HUVEC cell monolayer was scraped in a straight line to create a scratch with a p200 pipette tip. After scratching, the edge of the scratch was smoothened, and the debris was removed by washing twice with PBS, replaced with $1 \mathrm{~mL}$ of EGM-2, and observed by microscopy. The percentage of the closure area of the scratch was measured using ImageJ software until the scratch was closed entirely.

\section{Statistical Analysis}

All experiments were performed in triplicate to ensure reproducibility, and the data shown are representative results. Experimental values are presented as the mean \pm standard deviation. The significance of the differences between the control and treated samples was evaluated using a Student's $t$ test. Statistical significance was set at $p<0.05$.

\section{Results}

\section{P. gingivalis Infection Reduces PAI-1 Production in}

Human Endothelial Cells

PAI-1 produced by endothelial cells of the vascular endothelium regulates physiological functions such as hemostasis, wound healing, and inflammation $[11,27,28]$. In this study, we infected HUVECs - that constitutively produce high levels of PAI-1 under steady-state conditions (Fig. 1a) 
- with live P. gingivalis and measured the PAI-1 levels in the culture supernatant to determine whether $P$. gingivalis affects $\mathrm{PAI}-1$ production. Infection of live $P$. gingivalis W83 in HUVECs for $24 \mathrm{~h}$ resulted in a dose-dependent reduction in PAI-1 production (Fig. 1a), a phenomenon that continued until $48 \mathrm{~h}$ after infection (Fig. 1b). We did not observe any reduction in viability upon infecting the HUVECs with live $P$. gingivalis W83 at a multiplicity of infection (MOI) of 16 for $24 \mathrm{~h}$, which led us to conclude that infection-mediated cytotoxicity did not play a role in the reduction of PAI-1 production (online suppl. Fig. 2a; see www.karger.com/doi/10.1159/000519737 for all online suppl. material). However, the expression of PAI-1 mRNA (Fig. 1c) and PAI-1 protein levels (Fig. 1d) did not decrease until $24 \mathrm{~h}$ after $P$. gingivalis W83 infection (MOI of 16), indicating that the $P$. gingivalis-induced reduction in PAI-1 levels did not involve the downregulation of de novo protein synthesis in the endothelial cells. We then stimulated the HUVECs with lyophilized whole bacterial cells or $P$. gingivalis-derived OMVs to identify which components of $P$. gingivalis reduced PAI-1 production in the endothelial cells. Stimulation of HUVECs with lyophilized whole P. gingivalis W83 cells (Fig. 2a) or OMVs (Fig. 2b) resulted in significantly reduced PAI-1 production in a dose-dependent manner. Cytotoxicity was not responsible for reduced PAI-1 production upon stimulation with lyophilized whole cells or OMVs because the viability of HUVECs did not change (online suppl. Fig. 2b, c). Our investigation revealed that the PAI-1 production by HUVECs reduced significantly upon coculturing them with live $P$. gingivalis W83 cells even when cell culture inserts $(0.4 \mu \mathrm{m}$ pore size $)$ were used to separate the bacteria from HUVECs physically (Fig. 2c). However, the lyophilized P. gingivalis W83 whole cells failed to reduce PAI- 1 production by HUVECs in the presence of the filter (Fig. 2d). These results collectively indicated the involvement of secreted factors by live $P$. gingivalis and membrane-bound factors expressed on live P. gingivalis, lyophilized whole cells, and OMVs of $P$. gingivalis, in reducing PAI-1 production by endothelial cells. Furthermore, the expression levels of PAI-1 mRNA did not change significantly in the absence or presence of the filter (Fig. 2e, f). These results suggest that the induction of PAI-1 mRNA expression in endothelial cells may require recognizing bacterial cell wall components.

\section{P. gingivalis Gingipains Reduce PAI-1 Production in \\ Human Endothelial Cells}

$P$. gingivalis possesses two types of cysteine proteinases called gingipains, Rgps (RgpA and RgpB), and Kgp [6, 7]. We next examined whether gingipains degraded PAI-1,

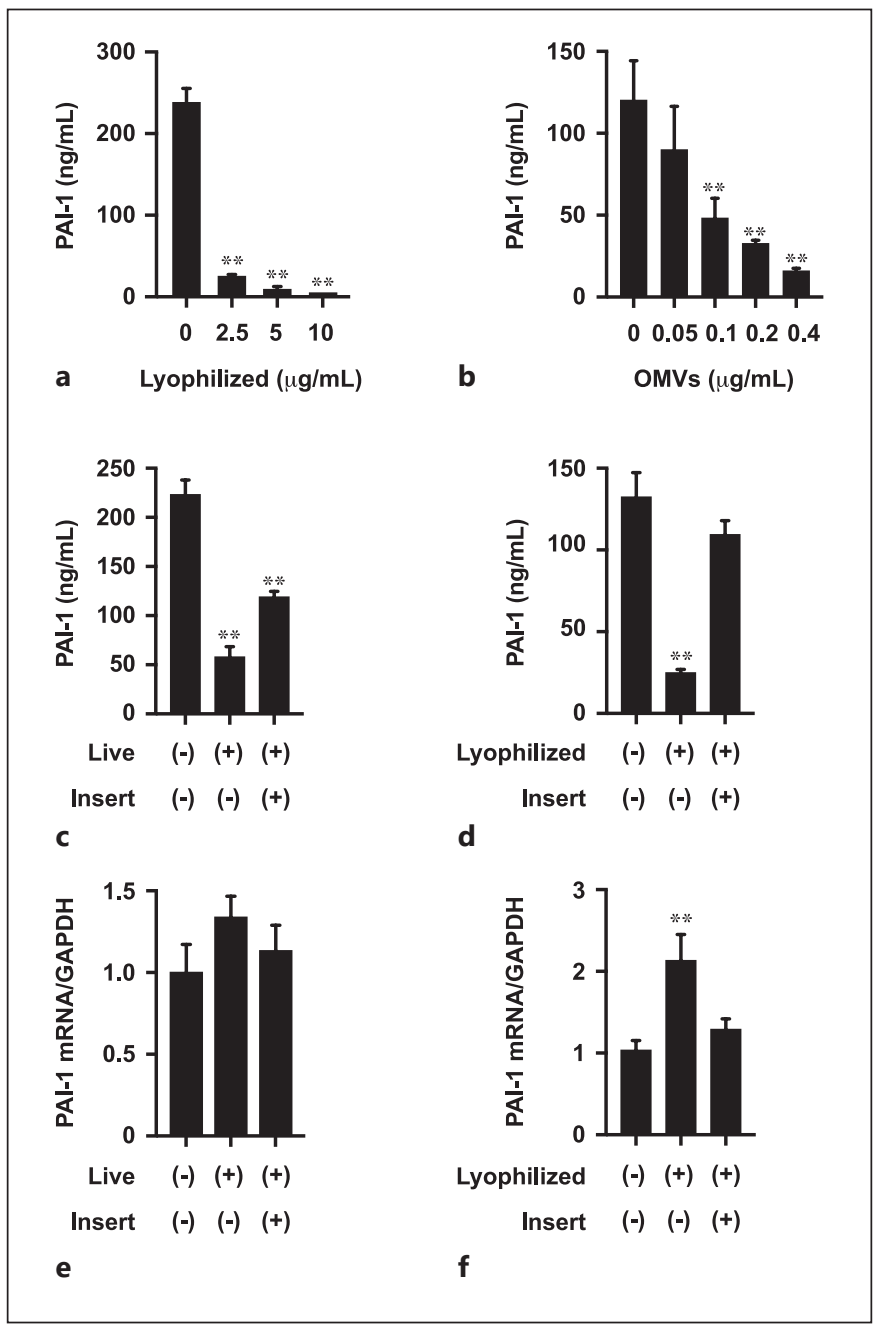

Fig. 2. Bacterial components derived from $P$. gingivalis reduce PAI-1 production in human endothelial cells. a, b HUVECs were stimulated with the indicated concentrations of lyophilized whole cells (a) or OMVs (b) derived from $P$. gingivalis W83 for $24 \mathrm{~h}$. c-f $P$. gingivalis W83 live bacteria at an MOI of 16 (c, e) or lyophilized whole cells at $5 \mu \mathrm{g} / \mathrm{mL}(\mathbf{d}, \mathbf{f})$ were added to the upper chamber, whereas HUVECs were cultured in the lower chamber. a-d The level of PAI-1 in the supernatants was analyzed using ELISA. e, f Total cellular RNA was extracted, and PAI- 1 transcripts were quantified by RT-qPCR. Data are representative of three independent experiments and are shown as means \pm SD. Statistically significant differences are indicated as follows: ${ }^{* *} p<0.01$ compared with the respective untreated control. PAI-1, plasminogen activator inhibitor-1; HUVECs, human umbilical vein endothelial cells; MOI, multiplicity of infection; ELISA, enzyme-linked immunosorbent assay; OMVs, outer membrane vesicles.

thereby reducing its levels by using $P$. gingivalis gingipaindeficient mutants. We used $P$. gingivalis strains lacking various combinations of gingipains to infect HUVECs and measured the resulting PAI-1 production (Fig. 3a). 


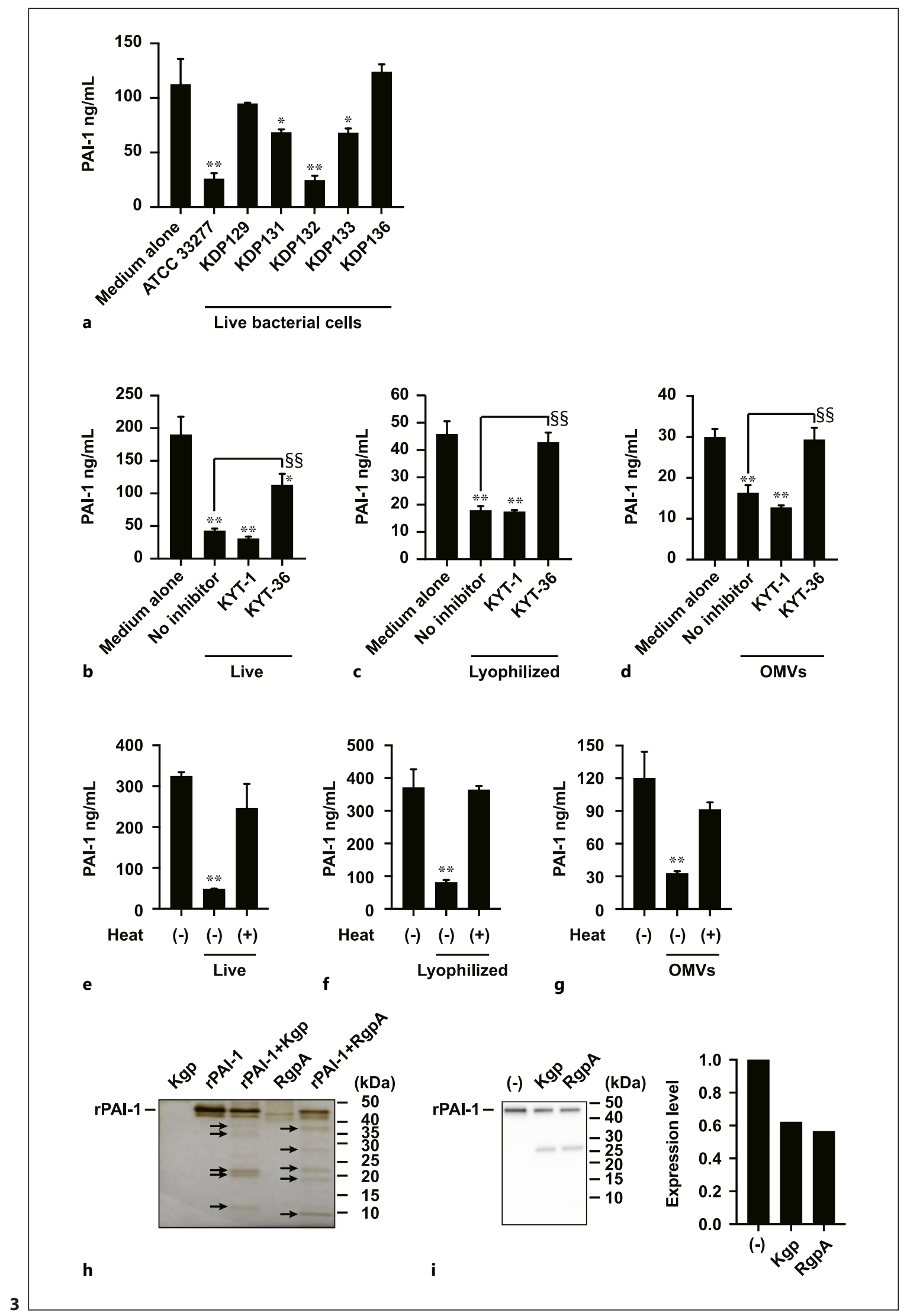

(For legend see next page.) 
We used live bacterial cells for this experiment (Fig. 3a) because Kgp and RgpA, but not RgpB, harbor the hemagglutinin/adhesin domains that enable these proteinases to be expressed on the $P$. gingivalis cell membrane [6]. Thus, the lyophilized whole bacterial cells did not express RgpB on the cell membrane. P. gingivalis ATCC 33277 is the wild-type parent strain of $P$. gingivalis mutants. We found that the live $P$. gingivalis W83 and ATCC 33277 strains were equally efficient at reducing PAI-1 production by HUVECs (data not shown). Moreover, $P$. gingivalis ATCC 33277 and KDP132 $(\Delta r g p B)$ equally and significantly reduced PAI-1 production by HUVECs (Fig. 3a). Infection with $P$. gingivalis KDP131 $(\Delta r g p A)$ or KDP133 ( $\Delta r g p A$ $\triangle \operatorname{rgp} B)$ partially, but significantly, reduced PAI-1 production by HUVECs, similar to ATCC 33277 (Fig. 3a). In contrast, $P$. gingivalis KDP129 $(\Delta k g p)$ or KDP136 ( $\Delta r g p A$ $\triangle r g p B \Delta k g p$ ) gingipain-null mutants did not significantly reduce PAI-1 production (Fig. 3a). These results suggest that Kgp is essential for the degradation of PAI- 1 and that RgpA is partially involved in PAI-1 degradation. We found that the reduction in PAI-1 production by HUVECs infected with live $P$. gingivalis W83 cells was also partially inhibited upon pretreatment with KYT-36 (Kgp inhibitor); however, the PAI-1 production in the cells infected with KYT-36-pretreated $P$. gingivalis significantly recovered compared to those infected with $P$. gingivalis without the inhibitor pretreatment (Fig. 3b). In contrast, HUVECs infected with $P$. gingivalis pretreated with KYT1 (Rgp inhibitor), the PAI-1 production did not recover compared with that in live P. gingivalis W83 cells (Fig. 3b). These results collectively indicated that the reduction in PAI-1 production by HUVECs in response to infection with live P. gingivalis was mediated by Kgp. Furthermore, the reduction in PAI-1 levels upon exposure to lyophilized whole cells or OMVs of $P$. gingivalis W83 was inhibited entirely upon exposure to lyophilized whole cells or

Fig. 3. Involvement of gingipains to attenuate PAI-1 production by human endothelial cells. a HUVECs were infected with live $P$. gingivalis ATCC 33277 (wild-type), P. gingivalis KDP129 ( $\Delta k g p)$, $P$. gingivalis $\mathrm{KDP} 131(\Delta r g p A), P$. gingivalis $\mathrm{KDP} 132(\triangle r g p B), P$. gingivalis $\mathrm{KDP} 133(\Delta r g p A \Delta r g p B)$, or $P$. gingivalis $\mathrm{KDP} 136(\Delta r g p A$ $\Delta r g p B \Delta k g p$ ) gingipain-null mutant bacteria at an MOI of 16 for $24 \mathrm{~h}$. b-d HUVECs were stimulated for $24 \mathrm{~h}$ with live bacteria (MOI of 16) (b), lyophilized whole cells $(5 \mu \mathrm{g} / \mathrm{mL})(\mathbf{c})$, or OMVs $(200 \mathrm{ng} / \mathrm{mL})(\mathbf{d})$ of $P$. gingivalis W83, or those pretreated with 1 $\mu \mathrm{M}$ of KYT-1 (Rgps inhibitor) or $1 \mu \mathrm{M}$ of KYT-36 (Kgp inhibitor) for $15 \mathrm{~min}$ at $37^{\circ} \mathrm{C}$. e-g PAI-1 production by HUVECs stimulated for 24 h with $P$. gingivalis W83 live bacteria (MOI of 16) (e), lyophilized whole cells $(5 \mu \mathrm{g} / \mathrm{mL})(\mathbf{f})$, and OMVs $(200 \mathrm{ng} / \mathrm{mL})(\mathbf{g})$, or preheated $\left(70^{\circ} \mathrm{C}\right.$ for $\left.1 \mathrm{~h}\right)$ of those. $\mathbf{a}-\mathbf{g}$ The amount of PAI-1 in
OMVs pretreated with KYT-36, but not with KYT-1 (Fig. 3c, d). PAI-1 production by HUVECs was not significantly different from that observed in the unstimulated control as it was from the infection conditions with the live bacteria, lyophilized whole cells, and OMVs of $P$. gingivalis W83, which were preheated at $70^{\circ} \mathrm{C}$ for $1 \mathrm{~h}$ to eliminate enzyme activity (Fig. $3 \mathrm{e}-\mathrm{g}$ ). We confirmed that the enzyme activities of Rgps and Kgp were intact in lyophilized whole cells (online suppl. Fig. 1a, b) or OMVs (online suppl. Fig. 1e, f) derived from $P$. gingivalis W83. Moreover, the activities of Rgp and Kgp in lyophilized whole $P$. gingivalis W83 were entirely inhibited by KYT-1 and KYT-36, respectively (online suppl. Fig. 1c, d). These results indicate an association between Kgp activity and the reduction in PAI-1 production induced by lyophilized whole cells or OMVs from $P$. gingivalis. We also treated recombinant human PAI-1 (rhPAI-1) $(44 \mathrm{kDa})$ with purified Kgp or RgpA, and the cleaved protein fragments of rhPAI-1 were detected using silver staining to demonstrate the proteolytic degradation of PAI-1 by gingipains. Our investigation did not reveal the presence of any cleaved protein fragments in the untreated rhPAI-1 control in the Tris buffer containing $0.5 \%$ BSA (Fig. $3 \mathrm{~h}$ ). However, five bands with molecular weights corresponding to $12,21,23,36$, and $48 \mathrm{kDa}$ were detected upon treating $454 \mathrm{nM}$ of rhPAI- 1 with $45.4 \mathrm{nM}$ of Kgp (Fig. 3h). Likewise, bands with molecular weights corresponding to 10 , $19,24,28$, and $38 \mathrm{kDa}$ were detected upon treating $454 \mathrm{nM}$ of rhPAI-1 with $45.4 \mathrm{nM}$ of RgpA (Fig. 3h). Furthermore, we found that the amount of rhPAI-1 decreased within 15 min after treatment with Kgp and RgpA (Fig. 3i). One band with a molecular weight of about $26 \mathrm{kDa}$ cleaved fragment by the treatment with Kgp and RgpA may be contained His-tag (Fig. 3i). However, this fragment could not be observed by silver staining because the amount of protein may be too small to observe (Fig. $3 \mathrm{~h}$ ). It has been

the culture supernatants was then analyzed by ELISA. h, i Recombinant human PAI-1 containing a His-tag was treated by purified Kgp or RgpA at $37^{\circ} \mathrm{C}$ for $15 \mathrm{~min}$, separated by SDS-PAGE, and then visualized by silver staining (h) or analyzed by Western blotting with an anti-His $\mathrm{mAb}(\mathbf{i})$. Arrow indicates the cleaved PAI-1 fragments. Data are representative of three $(\mathbf{a}-\mathbf{g})$ or two $(\mathbf{h}, \mathbf{i})$ independent experiments and are shown as means \pm SD. Statistically significant differences are indicated as follows: ${ }^{* *} p<0.01 ;{ }^{*} p$ $<0.05$ compared with the respective untreated control. ${ }^{\$ \$} p<0.01$ compared with the respective control that was not treated with the gingipain inhibitor. PAI-1, plasminogen activator inhibitor-1; HUVECs, human umbilical vein endothelial cells; MOI, multiplicity of infection; ELISA, enzyme-linked immunosorbent assay; OMVs, outer membrane vesicles. 
Fig. 4. Roles for PAI-1 in wound healing of endothelial cells. HUVECs grown in a cell monolayer were scratched, and then the cell migration after the injury was assessed by measuring the scratched area of the cells. a The closure of the scratched region of the untreated cells. Lines indicate margins of the scratched areas. b-d HUVECs were treated with the indicated concentrations of rhPAI-1 mutant (b), PAI-039 (PAI-1 inhibitor) (c), or rhPAI-1 mutant $(0.5 \mu \mathrm{g} / \mathrm{mL}) \pm$ the indicated concentrations of RAP (d) for the indicated times. The percentage of closure of the scratched area. Data are representative of three independent experiments and are shown as means \pm SD. Statistically significant differences are indicated as follows: ${ }^{* *} p<0.01 ;{ }^{*} p<$ 0.05 compared with the respective untreated control. PAI-1, plasminogen activator inhibitor-1; HUVECs, human umbilical vein endothelial cells; RAP, receptor-associated protein; rhPAI-1, recombinant human PAI-1.

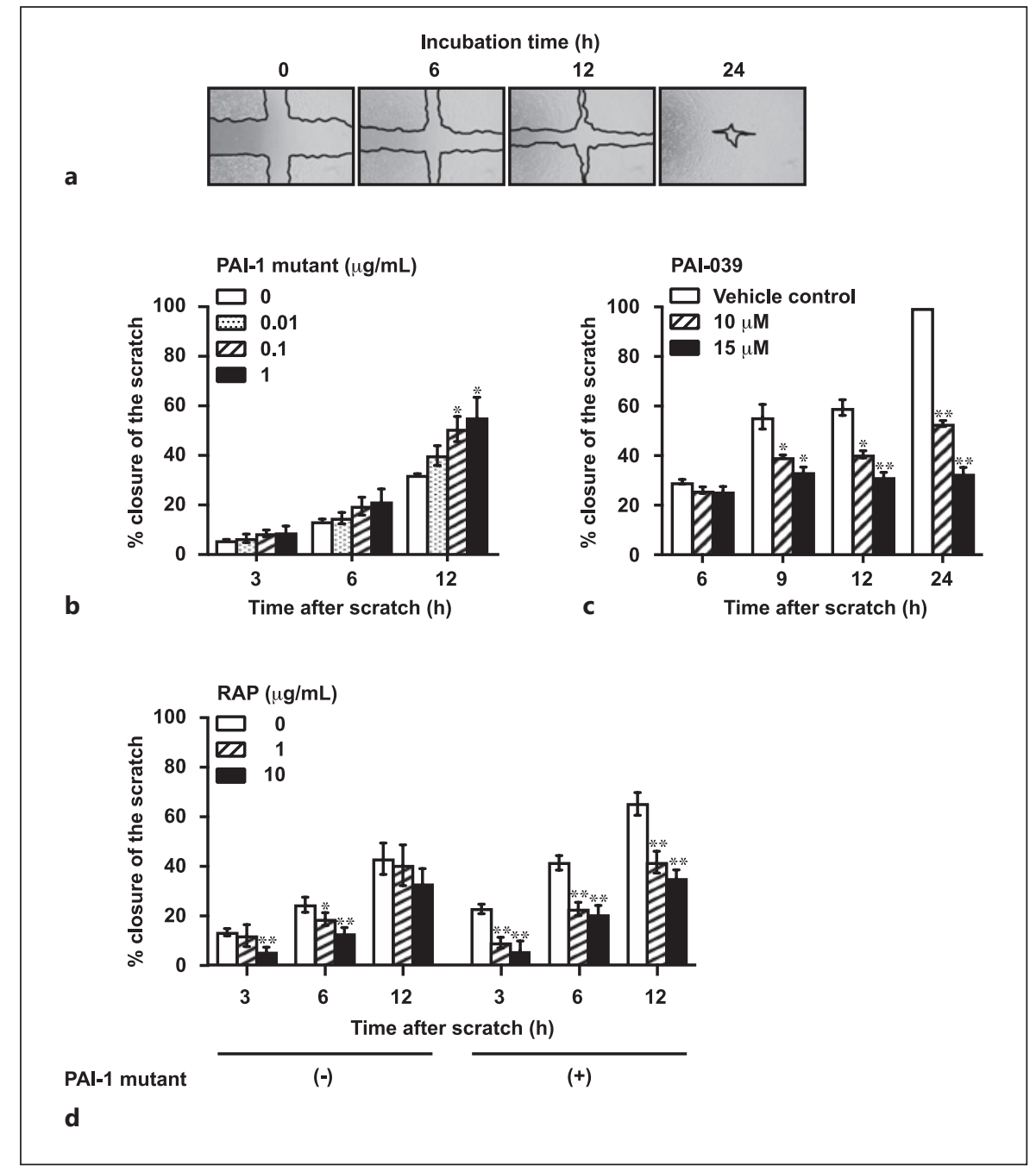

reported that gingipains alter antigenicity by degrading the epitope of the antigens expressed on the cell surface [8]. Therefore, to eliminate the possibility that gingipains alter the binding of anti-human PAI-1 antibody to recombinant human PAI-1, we next examined whether gingipains degraded PAI-1 by Western blotting using a recombinant human PAI-1 containing a His-tag. On the other hand, the cleaved fragments observed by silver staining (Fig. 3h) could not be observed in Western blotting (Fig. 3i), which may be intermediate fragments that do not contain the His-tag degraded by gingipains. These results showed that both Kgp and RgpA were equally capable of proteolytically cleaving rhPAI-1. Furthermore, Kgp efficiently reduced the production of PAI-1 by endothelial cells, indicating that rhPAI-1 is a substrate of gingipains and that the gingipain-digested fragments of PAI1 may lose their function.

Proteolytic Effect of Gingipains on PAI-1
Role of PAI-1 in Regulating HUVEC Migration during Wound Healing

It is known that PAI- 1 contributes to wound healing by promoting cell migration $[26,28]$. Endothelial cellproduced PAI-1 induces cell migration during the wound healing process in various pathological conditions of periodontitis $[27,29]$. We further examined whether the $P$. gingivalis-induced reduction in PAI-1 production affects endothelial cell migration using an in vitro scratch assay [26]. We found that when HUVECs cultured as a confluent monolayer were scraped, the scratched region almost completely closed after $24 \mathrm{~h}$ (Fig. 4a) [25]. We treated the HUVECs with recombinant human PAI-1 mutant to confirm whether the closure of the scratched region could be attributed to the endothelial cell-derived PAI-1-induced cell migration (Fig. 4b). We also observed that the closure of the scratched region of the HUVEC 
monolayer was significantly promoted in a dose-dependent manner $(0.1-1 \mu \mathrm{g} / \mathrm{mL}), 12 \mathrm{~h}$ after stimulation with the rhPAI-1 mutant (Fig. 4b; online suppl. Fig. 4a). Furthermore, our investigations revealed that the PAI-1-induced wound repair could not be attributed to promoting the cell proliferation induced by the PAI-1 mutant, as cell proliferation remained unchanged upon the treatment (online suppl. Fig. 4b). Moreover, the closure of the scratched region was inhibited by PAI-039, a PAI-1 inhibitor, to similar extent as the no inhibitor control (Fig. 4c; online suppl. Fig. 4c). The inhibition of wound repair could be attributed to reduced cell migration in the presence of PAI-039 as the cell proliferation of HUVECs was not affected by PAI-039 (online suppl. Fig. 4d). The closure of the scratched region in the HUVEC monolayer was also delayed by mitomycin C (online suppl. Fig. 3a, b) that inhibited cell migration and proliferation (online suppl. Fig. 3c) [30]. It has been reported that PAI-1 binds to the LRP on endothelial cells, thereby triggering the Janus kinase (JAK)/signal transducer and activator of transcription (STAT)-1-mediated signaling to promote endothelial cell migration [29]. Our data showed that the closure of the scratched region in the HUVEC monolayer was inhibited upon treatment with RAP, an LRP antagonist, 3 and $6 \mathrm{~h}$ after scratching (Fig. 4d; online suppl. Fig. 4 e). In addition, RAP also inhibited the promotion of wound repair by the PAI-1 mutant (Fig. 4d; online suppl. Fig. 4e). These data indicated that the wound healing response of HUVECs promoted the PAI-1-induced activation of LRP signaling. Therefore, it is suggested that the wound healing response of blood vessels requires the PAI-1-induced migration of endothelial cells, a signal transmitted via LRP in an autocrine manner.

\section{P. gingivalis Gingipains Induces a Delay in Human \\ Endothelial Cell Wound Healing}

We next investigated whether $P$. gingivalis attenuates the wound healing response of human endothelial cells using an in vitro scratch assay. A confluent HUVEC monolayer was scraped, and the closure of the scratched regions in the absence or presence of $P$. gingivalis was observed. The culture of HUVECs with live or lyophilized whole $P$. gingivalis W83 significantly delayed the closure of the scratched regions (Fig. 5a; online suppl. Fig. 5a). Our investigation confirmed that the delays in wound repair were not caused by the $P$. gingivalis-induced inhibition of HUVEC proliferation (online suppl. Fig. 5b). Moreover, we observed that the delays in wound repair of the HUVEC monolayers by the lyophilized whole P. gingivalis W83 and ATCC 33277 were significantly correct-
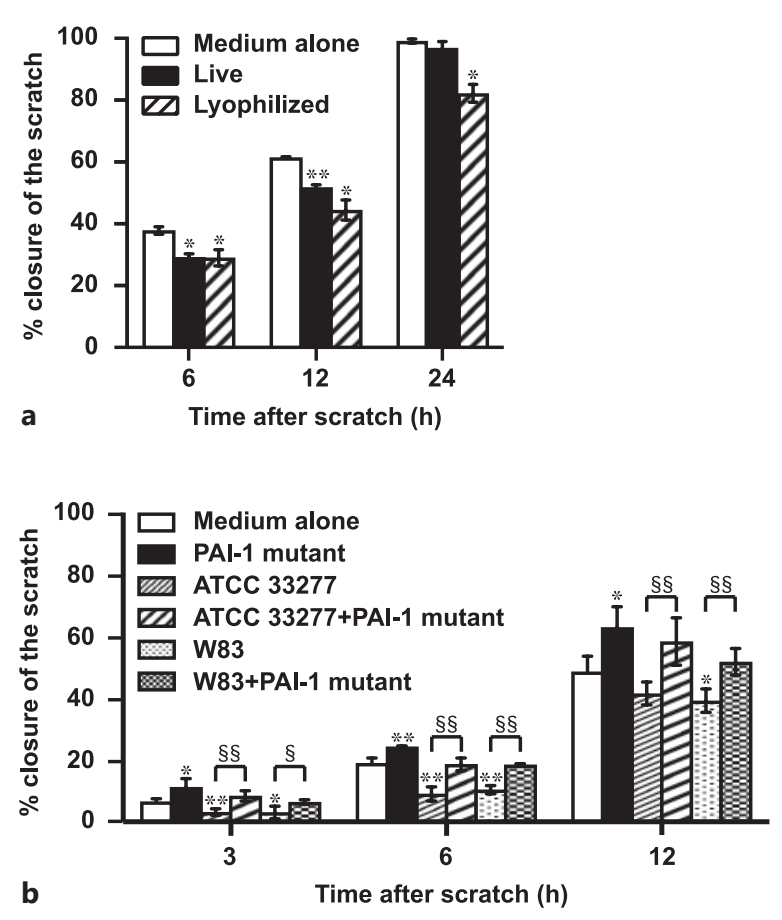

Fig. 5. $P$. gingivalis delays wound healing of endothelial cells in a PAI-1-dependent manner. HUVECs in a cell monolayer were scratched, then cell migration after the injury was assessed by measuring the scratched area of the cells. HUVECs were stimulated with live bacteria (MOI of 16) or lyophilized whole cells $(5 \mu \mathrm{g} / \mathrm{mL})$ of $P$. gingivalis W83 (a), or lyophilized whole cells $(5 \mu \mathrm{g} / \mathrm{mL})$ of $P$. gingivalis W83 or ATCC $33277 \pm$ rhPAI- 1 mutant $(0.5 \mu \mathrm{g} / \mathrm{mL})(\mathbf{b})$ for the indicated times. The percentage of closure of the scratched area. Data are representative of three independent experiments and are shown as means \pm SD. Statistically significant differences are indicated as follows: ${ }^{* *} p<0.01 ;{ }^{*} p<0.05$ compared with medium alone. ${ }^{\S \S} p<0.01 ;{ }^{\S} p<0.05$ compared with the respective control stimulated with $P$. gingivalis but not treated with the rhPAI-1 mutant. PAI-1, plasminogen activator inhibitor-1; HUVECs, human umbilical vein endothelial cells; MOI, multiplicity of infection; rhPAI-1, recombinant human PAI-1.

ed by the PAI-1 mutant (Fig. 5b; online suppl. Fig. 5c). These findings collectively indicated that $P$. gingivalis disturbed the PAI-1-dependent migration of endothelial cells, resulting in the attenuation of the wound healing response of the endothelial cell layer.

Next, we investigated whether the $P$. gingivalis-induced delayed wound healing response was mediated by gingipains. As expected, the wound closure was delayed in the cells infected with live $P$. gingivalis ATCC 33277 , but not in cells infected with live $P$. gingivalis KDP136 or heat-inactivated $P$. gingivalis ATCC 33277 (Fig. 6a; online suppl. Fig. 6a). HUVEC proliferation was also not altered 


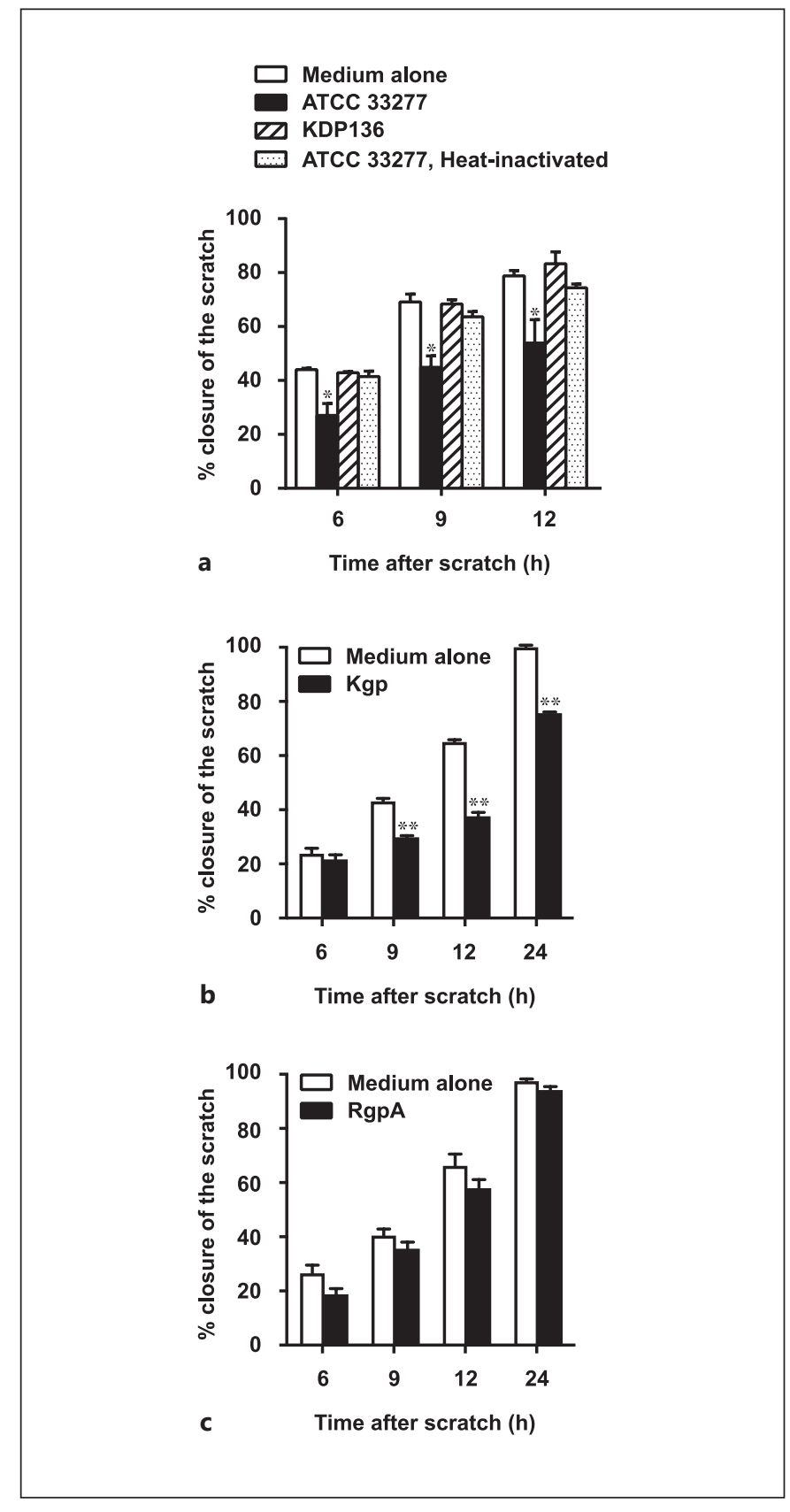

Fig. 6. Kgp preferentially induces the delay in wound healing of endothelial cells. HUVECs in a cell monolayer were scratched, and the cell migration after the injury was assessed by measuring the scratched area of the cells. a HUVECs were stimulated with live bacteria (MOI of 16) of $P$. gingivalis ATCC 33277, $P$. gingivalis KDP136, or heat-pretreated $\left(70^{\circ} \mathrm{C}\right.$ for $\left.1 \mathrm{~h}\right) P$. gingivalis ATCC 33277 for the indicated times. HUVECs were treated with purified $\operatorname{Kgp}(0.07 \mu \mathrm{M})(\mathbf{b})$ or $\operatorname{RgpA}(0.07 \mu \mathrm{M})(\mathbf{c})$ for the indicated times. Data are representative of three $(\mathbf{a})$ or two $(\mathbf{b}, \mathbf{c})$ independent experiments and are shown as means \pm SD. Statistically significant differences are indicated as follows: ${ }^{* *} p<0.01 ;^{*} p<0.05$ compared with the respective untreated control. HUVECs, human umbilical vein endothelial cells; MOI, multiplicity of infection.

Proteolytic Effect of Gingipains on PAI-1 upon infection with P. gingivalis ATCC 33277 or KDP136, suggesting the involvement of gingipains in inhibiting endothelial cell migration (online suppl. Fig. 6b). Depending on our findings so far, we further investigated the role of gingipains in the P. gingivalis-induced delayed wound healing response. The closure of the scratched regions of the HUVEC monolayer was significantly delayed upon treatment with Kgp (Fig. 6b; online suppl. Fig. 6c). However, there was no change in the closure of the scratched regions in RgpA-treated cell monolayers (Fig. 6c; online suppl. Fig. 6d). These results indicated that the degradation of PAI- 1 by Kgp played a critical role in the delayed wound healing response of human endothelial cells. These findings suggest that $P$. gingivalis induces Kgp-mediated degradation of PAI-1, a phenomenon that attenuates LRP-mediated cell migration, resulting in the delayed wound healing response of the endothelial cell layer.

\section{Discussion}

In this study, we utilized multiple approaches to demonstrate that $P$. gingivalis infection reduces PAI-1 production in human endothelial cells using HUVECs. Gingival endothelial cells isolated from periodontally healthy individuals exhibit the production of PAI- 1 constitutively [31]. The reduction of PAI-1 production by endothelial cells resulted from the proteolytic cleavage of PAI-1 by bacterial proteinases, gingipains. A reduction in PAI-1 production attenuates the migration of endothelial cells, leading to a delay in their wound healing responses, which involved in the activation of LRP-mediated signaling by PAI-1 in an autocrine manner. Based on these results, we have provided evidence that the degradation of PAI- 1 by purified gingipains delays the wound healing responses of the endothelium cell layer, which might induce the dysfunction of vascular endothelium and the bleeding of periodontal tissues, resulting in the invasion of oral bacteria into the blood vessels. These findings suggest that $P$. gingivalis may manipulate the innate immune system of the blood vessels by using bacterial proteinases to degrade PAI-1 produced by endothelial cells, thereby spreading the bacterial infection from periodontal tissues.

PAI-1 localizes in the gingival epithelium and connective tissue, and its expression levels are almost comparable in the gingival tissues of healthy individuals and patients with chronic periodontitis [32]. Furthermore, PAI1 expression was not elevated in inflamed gingiva in experimental periodontitis [33]. Periodontitis is a mixed 
infection and the periodontopathogenic bacteria form biofilms in the subgingival environment. Activation of plasminogen-bound Fusobacterium nucleatum, a periodontopathogenic bacteria, by uPA significantly induced the degradation of fibronectin or the tissue inhibitor of metalloproteinase-1, thereby promoting host tissue destruction [34]. These findings suggest that the decrease in PAI-1 levels due to the gingipain-induced degradation of PAI-1 may cause the destruction of periodontal tissues via the activation of $\mathrm{UPA}$. In contrast to PAI-1 expression in periodontal tissues, PAI-1 levels are elevated in the plasma of patients with severe chronic periodontitis and are associated with the degree of inflammatory responses in periodontal tissues [35]. The expression of PAI-1 mRNA is induced by bacterial lipoprotein via TLR2 expressed on endothelial cells [36], and $P$. gingivalis has been reported to invade endothelial cells [37-40]. Invaded endothelial cells have been shown to produce PAI-1 upon infection with large numbers of $P$. gingivalis at an MOI of 100, but not upon infection with a noninvasive strain of $P$. gingivalis that lacks fimbriae [41]. In blood vessels, a clearance of fibrin is carried out by plasmin, which is converted from plasminogen through the binding of tPA, which has been shown to exacerbate atherosclerosis [42]. Since endothelial cells produce both PAI-1 and $\mathrm{TPA}$, increased PAI-1 production leads to the inactivation of PAs [43]. These findings suggest that $P$. gingivalis may induce an inflammatory response in endothelial cells and blood vessels, exacerbating systemic diseases such as atherosclerosis. In fact, $P$. gingivalis induces PAI1 expression in human endothelial cells and human platelets $[23,41]$. The results of our study corroborate the findings from such studies by highlighting how PAI-1 is degraded by gingipains from $P$. gingivalis in the periodontal tissues. Taking these findings, together with our results, into consideration, the function of PAI- 1 in periodontitis may have two implications: (a) the decreased PAI-1 level in periodontal tissues may cause the delayed wound repair of the endothelium, and the bleeding and destruction of periodontal tissues by the activation of PAs, and (b) the increased PAI-1 level in blood vessels may cause the attenuation of plasminogen activation system by the inactivation of PAs.

Our study revealed how PAI-1 production in HUVECs was markedly reduced by stimulating lyophilized whole cells expressing Kgp and RgpA on the cell membrane (Fig. 2a). This PAI-1 reduction was abolished when the lyophilized whole cells were preheated $\left(1 \mathrm{~h}\right.$ at $\left.70^{\circ} \mathrm{C}\right)$ to inactivate the enzyme activity (Fig. 3f). Furthermore, the PAI-1 reduction in response to exposure to the ly- ophilized whole cells was abolished in the coculture system using cell culture inserts (Fig. 2d), suggesting the role of Kgp and RgpA in the reduction of PAI- 1 production by endothelial cells. Moreover, a previous report has demonstrated how the production of PAI-1 in human platelets induced by $\mathrm{Pam}_{3} \mathrm{CSK}_{4}$, a TLR2 ligand, is attenuated by $P$. gingivalis, but not by the Kgp-deficient strain [23]. PAI-1 production in HUVECs was not reduced upon infection with $P$. gingivalis KDP129 $(\Delta k g p)$ and KDP136 ( $\Delta k g p \Delta r g p A \Delta r g p B)$ (Fig. 3a). However, the reduced PAI-1 production in HUVECs partially recovered upon infection with $P$. gingivalis $\mathrm{KDP} 131(\triangle r g p A)$ and KDP133 $(\triangle \operatorname{rgp} A \Delta r g p B)$, but not upon infection with P. gingivalis KDP132 ( $\triangle r g p B)$ (Fig. 3a). These results collectively indicated that the efficiency of gingipins to degrade PAI-1 is more dependent on Kgp than on RgpA. Moreover, RgpB also did not exhibit PAI-1-reducing activity. Our experiments to determine the reaction of rhPAI-1 with purified gingipains revealed that Kgp and RgpA had almost equal efficiency with respect to promoting gingipain-mediated degradation of rhPAI-1 (Fig. 3i). We hypothesized three possibilities that could explain the higher efficiency of Kgp to degrade PAI-1 than the Rgps. First, Kgp and RgpA bind to fibrinogen, fibronectin, and laminin because hemagglutinin/adhesin domains augment the cleavage of fibrinogen by the catalytic domain of gingipains [44], indicating that the hemagglutinin/adhesin domain may effectively bind to PAI-1. Second, it has been reported that RgpA and Kgp form membranebound complexes, outer membrane vesicles, and soluble forms and exert major pathogenic factors [44, 45]. Fleetwood et al. [46] reported that the RgpA-Kgp complex efficiently cleaves pro-uPA, a precursor of uPA, and plasminogen, yielding active uPA and plasmin, respectively. Third, proteinase inhibitors may inhibit Rgps activity. It has been reported that Kgp digests fibrinogen more effectively than Rgp in the presence of the plasma [47, 48]. Kgp is the most potent fibrinogen/fibrin-degrading enzyme of the three gingipains in the presence of the human plasma [47]. The enzyme activities of Rgps are inhibited by the plasma proteinase inhibitor a2-macroglobulin, while Kgp is resistant [49]. Moreover, $\alpha 2$-macroglobulin has also been found in FBS [50]. In this study, recombinant PAI-1 was treated with purified gingipains using a buffer in the presence of $0.5 \%$ BSA (Fig. 3i) as PAI- 1 is stabilized by interaction with plasma components, such as vitronectin [29]. PAI-1 is synthesized in the active conformation but spontaneously converts to a latent form with a relatively short active half-life of $1-2 \mathrm{~h}[25,29]$. Importantly, as our experiments aimed at measuring 
PAI-1 produced by HUVECs stimulated with $P$. gingivalis used a medium containing $2 \% \mathrm{FBS}$, proteinase inhibitors in the serum may inhibit the degradation of PAI- 1 by Rgps.

Endothelial cells are the main cellular constituents of blood vessels and separate blood from the underlying tissues. It is known that PAI-1 plays a vital role in the migration of immune cells at the site of inflammation [51,52]. In this study, the delays in wound repair by the HUVEC monolayers caused by $P$. gingivalis were significantly rescued by adding PAI-1 mutant (Fig. 5b; online suppl. Fig. 5c). These results suggest that the degradation of PAI-1 by $P$. gingivalis caused the delay in wound healing. Furthermore, the wound closure was delayed in the cells cocultured with $P$. gingivalis ATCC 333277, but not in cells cocultured with live $P$. gingivalis KDP136 or heat-inactivated P. gingivalis ATCC 33277 (Fig. 6a; online suppl. Fig. 6a). In addition, the wound healing responses of the HUVEC monolayers depended on PAI-1 produced by the cells because $15 \mu \mathrm{M}$ of PAI-039 completely inhibited the wound closure (Fig. 4b; online suppl. Fig. 4c), but not the cell proliferation (online suppl. Fig. 4d). These results suggested that the recovery of the delay in wound healing by $P$. gingivalis KDP136 or heat-inactivated $P$. gingivalis was probably responsible for protecting the degradation of PAI-1. PAI-1 expressed in smooth muscle cells regulates cell migration by activating the LRP and the downstream JAK/ STAT signaling pathway [29]. Furthermore, PAI-039 inhibits the migration of smooth muscle cells in an STAT1dependent manner [53]. In this study, the wound healing of the HUVEC monolayers was inhibited by PAI-039 and RAP, and this effect was mediated through PAI-1-induced autocrine activation of LRP signaling (Fig. $4 \mathrm{c}$, d; online suppl. Fig. 4c, e). The delayed wound healing responses were probably due to the degradation of PAI-1 in HUVECs by gingipains restored by adding the PAI-1 mutant (Fig. 5b; online suppl. Fig. 5c). PAI-1 produced by endothelial cells plays a role in tissue remodeling during wound repair in the vascular endothelium of periodontal tissues [28].

In chronic periodontitis, bleeding from periodontal pockets is beneficial for $P$. gingivalis because the bacterium requires hemin, which comes from erythrocytes, for the growth of the bacterium $[54,55]$. Kgp plays an indispensable role in the release of hemin from hemoglobin $[56,57]$. In this study, wound repair of the HUVEC monolayers was also delayed upon treatment with purified Kgp (Fig. 6b; online suppl. Fig. 6c). The decreasing level of PAI-1 leads to excessive fibrinolysis due to the processing of plasminogen to plasmin, resulting in bleeding caused by insufficient wound healing responses [58]. Taken together, the Kgp-

Proteolytic Effect of Gingipains on PAI-1 mediated decrease in PAI-1 levels is associated with promoting fibrinolysis and contributing to the bleeding tendency in periodontal tissues [59]. In summary, we hypothesized that the degradation of endothelial cell-derived PAI-1 by $P$. gingivalis gingipains delayed endothelial wound repair, resulted in increased bleeding risks, promotion of periodontal tissue destruction, and spreading of the $P$. gingivalis infection from the periodontal tissue to various other systemic organs via the bloodstream.

\section{Acknowledgments}

The authors would like to thank M. Naito and K. Nakayama (Nagasaki University, Japan) for providing the mutant $P$. gingivalis strains. We are grateful to Editage (www.editage.jp) for English language editing.

\section{Statement of Ethics}

No ethical approval was sought as this research did not require animal or human involvement.

\section{Conflict of Interest Statement}

The authors declare no conflicts of interest.

\section{Funding Sources}

This work was supported by grants from the Japan Society for the Promotion of Science KAKENHI (Grant No. 19K10143 to H. Tada, Grant No. 20H03904 to K. Matsushita) and the Research Funding for Longevity Sciences from National Center for Geriatrics and Gerontology (Grant No. 29-25 to K. Matsushita).

\section{Author Contributions}

H. Tada and L.-T. Song conceived and designed the study, performed data acquisition and analysis, contributed to the interpretation of the data, prepared the figures, and drafted the manuscript. T. Nishioka, E. Nemoto, and T. Imamura provided technical supports. J. Potempa, C.-Y. Li, K. Matsushita, and S. Sugawara contributed to the interpretation of the data. All authors reviewed, revised, and approved the final manuscript.

\section{Data Availability Statement}

All data generated or analyzed during this study are included in this article and its online supplementary files. Further inquiries can be directed to the corresponding author upon reasonable request. 


\section{References}

1 Haraszthy VI, Zambon JJ, Trevisan M, Zeid $\mathrm{M}$, Genco RJ. Identification of periodontal pathogens in atheromatous plaques. J Periodontol. 2000 Oct;71(10):1554-60.

2 Kozarov EV, Dorn BR, Shelburne CE, Dunn WA, Progulske-Fox A. Human atherosclerotic plaque contains viable invasive Actinobacillus actinomycetemcomitans and Porphyromonas gingivalis. Arterioscler Thromb Vasc Biol. 2005 Mar;25(3):e17-8.

3 Socransky SS, Haffajee AD, Cugini MA, Smith C, Kent RL. Microbial complexes in subgingival plaque. J Clin Periodontol. 1998 Feb;25(2):134-44.

4 Zaremba M, Górska R, Suwalski P, Kowalski J. Evaluation of the incidence of periodontitis-associated bacteria in the atherosclerotic plaque of coronary blood vessels. J Periodontol. $2007 \mathrm{Feb} ; 78(2): 322-7$.

5 Potempa J, Mydel P, Koziel J. The case for periodontitis in the pathogenesis of rheumatoid arthritis. Nat Rev Rheumatol. 2017 Oct; 13(10):606-20.

6 Pike R, McGraw W, Potempa J, Travis J. Lysine- and arginine-specific proteinases from Porphyromonas gingivalis. Isolation, characterization, and evidence for the existence of complexes with hemagglutinins. J Biol Chem. 1994 Jan;269(1):406-11.

7 Potempa J, Sroka A, Imamura T, Travis J. Gingipains, the major cysteine proteinases and virulence factors of Porphyromonas gingivalis: structure, function and assembly of multidomain protein complexes. Curr Protein Pept Sci. 2003 Dec;4(6):397-407.

8 Imamura T. The role of gingipains in the pathogenesis of periodontal disease. J Periodontol. 2003 Jan;74(1):111-8.

9 Potempa J, Korzus E, Travis J. The serpin superfamily of proteinase inhibitors: structure, function, and regulation. J Biol Chem. 1994 Jun;269(23):15957-60.

10 Van De Craen B, Declerck PJ, Gils A. The biochemistry, physiology and pathological roles of PAI- 1 and the requirements for PAI- 1 inhibition in vivo. Thromb Res. 2012 Oct; 130(4):576-85.

11 Becker BF, Heindl B, Kupatt C, Zahler S. Endothelial function and hemostasis. Z Kardiol. $2000 \mathrm{Mar} ; 89(3): 160-7$.

12 Lijnen HR. Pleiotropic functions of plasminogen activator inhibitor-1. J Thromb Haemost. 2005 Jan;3(1):35-45.

13 Gopal S, Garibaldi S, Goglia L, Polak K, Palla G, Spina S, et al. Estrogen regulates endothelial migration via plasminogen activator inhibitor (PAI-1). Mol Hum Reprod. 2012 Aug; 18(8):410-6.

14 Yamamoto K, Takeshita K, Kojima T, Takamatsu J, Saito H. Aging and plasminogen activator inhibitor-1 (PAI-1) regulation: implication in the pathogenesis of thrombotic disorders in the elderly. Cardiovasc Res. 2005 May;66(2):276-85.
15 Diéval J, Nguyen G, Gross S, Delobel J, Kruithof EK. A lifelong bleeding disorder associated with a deficiency of plasminogen activator inhibitor type 1. Blood. $1991 \mathrm{Feb} ; 77(3)$ : 528-32.

16 Fay WP, Parker AC, Condrey LR, Shapiro AD. Human plasminogen activator inhibitor-1 (PAI-1) deficiency: characterization of a large kindred with a null mutation in the PAI1 gene. Blood. 1997 Jul;90(1):204-8.

17 Shapiro A. The use of prophylaxis in the treatment of rare bleeding disorders. Thromb Res. 2020 Dec;196:590-602.

18 Sillen M, Declerck PJ. Targeting PAI-1 in cardiovascular disease: structural insights into PAI-1 functionality and inhibition. Front Cardiovasc Med. 2020 Dec;7:622473.

19 Lockhart PB, Brennan MT, Sasser HC, Fox PC, Paster BJ, Bahrani-Mougeot FK. Bacteremia associated with toothbrushing and dental extraction. Circulation. 2008 Jun;117(24): 3118-25.

20 Dominy SS, Lynch C, Ermini F, Benedyk M, Marczyk A, Konradi A, et al. Porphyromonas gingivalis in Alzheimer's disease brains: evidence for disease causation and treatment with small-molecule inhibitors. Sci Adv. 2019 Jan;5(1):eaau3333.

21 Tonetti MS, D'Aiuto F, Nibali L, Donald A, Storry C, Parkar M, et al. Treatment of periodontitis and endothelial function. N Engl J Med. 2007 Mar;356(9):911-20.

22 Yamazaki K, Ohsawa Y, Itoh $\mathrm{H}$, Ueki K, Tabeta K, Oda T, et al. T-cell clonality to Porphyromonas gingivalis and human heat shock protein $60 \mathrm{~s}$ in patients with atherosclerosis and periodontitis. Oral Microbiol Immunol. 2004 Jun;19(3):160-7.

23 Klarström Engström K, Khalaf H, Kälvegren $\mathrm{H}$, Bengtsson T. The role of Porphyromonas gingivalis gingipains in platelet activation and innate immune modulation. Mol Oral Microbiol. 2015 Feb;30(1):62-73.

24 Kadowaki T, Baba A, Abe N, Takii R, Hashimoto M, Tsukuba T, et al. Suppression of pathogenicity of Porphyromonas gingivalis by newly developed gingipain inhibitors. Mol Pharmacol. 2004 Dec;66(6):1599-606.

25 Berkenpas MB, Lawrence DA, Ginsburg D. Molecular evolution of plasminogen activator inhibitor-1 functional stability. EMBO J. 1995 Jul;14(13):2969-77.

26 Liang CC, Park AY, Guan JL. In vitro scratch assay: a convenient and inexpensive method for analysis of cell migration in vitro. Nat Protoc. 2007;2(2):329-33.

27 Simone TM, Higgins PJ. Inhibition of SERPINE1 function attenuates wound closure in response to tissue injury: a role for PAI-1 in re-epithelialization and granulation tissue formation. J Dev Biol. 2015;3(1):11-24.

28 Wyganowska-Świątkowska M, Surdacka A, Skrzypczak-Jankun E, Jankun J. The plasminogen. activation system in periodontal tissue. Int J Mol Med. 2014 Apr;33(4):763-8.
29 Degryse B, Neels JG, Czekay R, Aertgeerts K, Kamikubo Y, Loskutoff DJ. The low density lipoprotein receptor-related protein is a motogenic receptor for plasminogen activator inhibitor-1. J Biol Chem. 2004 May;279(21): 22595-604.

30 Seki Y, Toba K, Fuse I, Sato N, Niwano H, Takahashi $\mathrm{H}$, et al. In vitro effect of cyclosporin $\mathrm{A}$, mitomycin $\mathrm{C}$ and prednisolone on cell kinetics in cultured human umbilical vein endothelial cells. Thromb Res. 2005;115(3):21928.

31 Decarlo AA, Cohen JA, Aguado A, Glenn B. Isolation and characterization of human gingival microvascular endothelial cells. J Periodontal Res. 2008 Apr;43(2):246-54.

32 Xiao Y, Bunn CL, Bartold PM. Immunohistochemical demonstration of the plasminogen activator system in human gingival tissues and gingival fibroblasts. J Periodontal Res. 1998 Jan;33(1):17-26.

33 Papadimitriou S, Tsantarliotou M, Makris G, Papaioannou N, Batzios Ch, Kokolis N, et al. A clinical study of plasminogen activator activity in gingival tissue in dogs with gingivitis and periodontitis. Res Vet Sci. 2006 Apr; 80(2):189-93.

34 Darenfed H, Grenier D, Mayrand D. Acquisition of plasmin activity by Fusobacterium nucleatum subsp. nucleatum and potential contribution to tissue destruction during periodontitis. Infect Immun. 1999 Dec;67(12): 6439-44.

35 Bizzarro S, Van Der Velden U, Ten Heggeler JMAG, Leivadaros E, Hoek FJ, Gerdes VE, et al. Periodontitis is characterized by elevated PAI-1 activity. J Clin Periodontol. 2007 Jul; 34(7):574-80.

36 Shin HS, Xu F, Bagchi A, Herrup E, Prakash A, Valentine C, et al. Bacterial lipoprotein TLR2 agonists broadly modulate endothelial function and coagulation pathways in vitro and in vivo. J Immunol. 2011 Dec;186(2): 1119-30.

37 Deshpande RG, Khan MB, Genco CA. Invasion of aortic and heart endothelial cells by Porphyromonas gingivalis. Infect Immun. 1998 Nov;66(11):5337-43.

38 Dorn BR, Dunn WA, Progulske-Fox A. Invasion of human coronary artery cells by periodontal pathogens. Infect Immun. 1999 Nov; 67(11):5792-8.

39 Ho MH, Guo ZM, Chunga J, Goodwin JS, Xie $\mathrm{H}$. Characterization of innate immune responses of human endothelial cells induced by Porphyromonas gingivalis and their derived outer membrane vesicles. Front Cell Infect Microbiol. 2016 Oct;6:139.

40 Roth GA, Moser B, Roth-Walter F, Giacona MB, Harja E, Papapanou PN, et al. Infection with a periodontal pathogen increases mononuclear cell adhesion to human aortic endothelial cells. Atherosclerosis. $2007 \mathrm{Feb} ; 190(2)$ : 271-81. 
41 Roth GA, Moser B, Huang SJ, Brandt JS, Huang Y, Papapanou PN, et al. Infection with a periodontal pathogen induces procoagulant effects in human aortic endothelial cells. J Thromb Haemost. 2006 Oct;4(10):2256-61.

42 Vaughan DE. PAI-1 and atherothrombosis. J Thromb Haemost. 2005 Aug;3(8):1879-83.

43 Kooistra T, Schrauwen Y, Arts J, Emeis JJ. Regulation of endothelial cell t-PA synthesis and release. Int J Hematol. 1994 Jun;59(4): 233-55.

44 Pathirana RD, O’Brien-Simpson NM, Veith PD, Riley PF, Reynolds EC. Characterization of proteinase-adhesin complexes of Porphyromonas gingivalis. Microbiology. 2006 Aug; 152(8):2381-94.

45 Rajapakse PS, O'Brien-Simpson NM, Slakeski N, Hoffmann B, Reynolds EC. Immunization with the RgpA-Kgp proteinase-adhesin complexes of Porphyromonas gingivalis protects against periodontal bone loss in the rat periodontitis model. Infect Immun. 2002 May; 70(5):2480-6.

46 Fleetwood AJ, O'Brien-Simpson NM, Veith $\mathrm{PD}$, Lam RS, Achuthan A, Cook AD, et al. Porphyromonas gingivalis-derived RgpAKgp complex activates the macrophage urokinase plasminogen activator system: implications for periodontitis. J Biol Chem. 2015 Jun; 290(26): 16031-42.

47 Scott CF, Whitaker EJ, Hammond BF, Colman RW. Purification and characterization of a potent $70-\mathrm{kDa}$ thiol lysyl-proteinase (Lysgingivain) from Porphyromonas gingivalis that cleaves kininogens and fibrinogen. J Biol Chem. 1993 Apr;268(11):7935-42.

48 Imamura T, Potempa J, Pike RN, Moore JN, Barton MH, Travis J. Effect of free and vesiclebound cysteine proteinases of Porphyromonas gingivalis on plasma clot formation: implications for bleeding tendency at periodontitis sites. Infect Immun. 1995 Dec;63(12): 4877-82.

49 Gron H, Pike R, Potempa J, Travis J, Thogersen IB, Enghild JJ, et al. The potential role of a2-macroglobulin in the control of cysteine proteinases (gingipains) from Porphyromonas gingivalis. J Periodont Res. 1997 Jan; 32(1):61-8.

50 Dangott LJ, Cunningham LW. Residual alpha 2-macroglobulin in fetal calf serum and properties of its complex with thrombin. Biochem Biophys Res Commun. 1982 Aug;107(4): 1243-51.

51 McMahon GA, Petitclerc E, Stefansson S, Smith E, Wong MK, Westrick RJ, et al. Plasminogen activator inhibitor-1 regulates tumor growth and angiogenesis. J Biol Chem. 2001 Sep;276(36):33964-8.

52 Czekay RP, Aertgeerts K, Curriden SA, Loskutoff DJ. Plasminogen activator inhibitor-1 detaches cells from extracellular matrices by inactivating integrins. J Cell Biol. 2003;160(5): 781-91.
53 Ji Y, Weng Z, Fish P, Goyal N, Luo M, Myears SP, et al. Pharmacological targeting of plasminogen activator inhibitor- 1 decreases vascular smooth muscle cell migration and neointima formation. Arterioscler Thromb Vasc Biol. 2016 Nov;36(11):2167-75.

54 Lamont RJ, Jenkinson HF. Life below the gum line: pathogenic mechanisms of Porphyromonas gingivalis. Microbiol Mol Biol Rev. 1998 Dec;62(4):1244-63.

55 Lewis JP. Metal uptake in host-pathogen interactions: role of iron in Porphyromonas gingivalis interactions with host organisms. Periodontol 2000. 2010 Feb;52(1):94-116.

56 Lewis JP, Dawson JA, Hannis JC, Muddiman D, Macrina FL. Hemoglobinase activity of the lysine gingipain protease (Kgp) of Porphyromonas gingivalis W83. J Bacteriol. 1999 Aug;181(16):4905-13.

57 Sroka A, Sztukowska M, Potempa J, Travis J, Genco CA. Degradation of host heme proteins by lysine- and arginine-specific cysteine proteinases (gingipains) of Porphyromonas gingivalis. J Bacteriol. 2001 Oct;183(19):5609-16.

58 Daniel AE, Timmerman I, Kovacevic I, Hordijk PL, Adriaanse L, Paatero I, et al. Plasminogen activator inhibitor- 1 controls vascular integrity by regulating VE-cadherin trafficking. PLoS One.2015 Dec;10(12):e0145684.

59 Mehta R, Shapiro AD. Plasminogen activator inhibitor type 1 deficiency. Haemophilia. 2008 Nov;14(6):1255-60. 